\title{
Experimental Evaluation on Different Viscous Fluids Spray Characteristics in Injector Using Constant Volume Chamber
}

\author{
K.Vinukumar
}

\begin{abstract}
Atomization of liquids is a complicated process. It is common in many industries such as automotive, manufacturing (spray drying) and mineral processing. This kind of simplex injector finds its use in combustor. The need to minimize the combustor length usually leads to a spray angle of around $90^{\circ}$. The experimental investigations of simplex injector for spray cone angle at different injection pressure ranging from $0.5 \mathrm{bar}$ to $3 \mathrm{bar}$ in an increment of 0.5bar. The results are then compared with different injector dimensions of $1 \mathrm{~mm}, 1.5 \mathrm{~mm}$ and $2.5 \mathrm{~mm}$ and different fuels such as kerosene, bio diesel from cotton seed oil. The discharge coefficient and the spray cone angle were evaluated experimentally and compared with the theory used to design the injector. The spray cone angle was measured with the Shadow graphic Technique.
\end{abstract}

Keywords - Injector, Spray cone angle, Shadow graphic Technique, Combustor, Different fuels

\section{INTRODUCTION}

Injector is common place in numerous engineering applications in which a liquid must be broken down into droplets, such as in combustion, drying, or agriculture. Spray is a common method for spreading liquids in various situations. Spray development in various technological applications, including process industries (spray drying, spray cooling), coating application (surface treatment, spray painting), spray combustion (burners, furnaces, internal combustion piston engines, jet engine combustion, and rocket motors) and medical and printing application [5-8].

Spray characteristics of the fuel mainly depend on the injection pressure, fuel density, fuel viscosity, ambient gas pressure and temperature. Spray cone angle is often the main subject of the experimental investigations [2]. Discharge coefficient, varying injector dimensions are also parameters of interest. The injector was expected to perform within certain ranges of discharge coefficient, cone angle. Therefore, the injector had to be redesigned, varying their dimensions. A systematic study of the influence of geometry and injection conditions on discharge coefficient, cone angle was conducted. Spray cone-angle measurements, comparison with existing correlations, and a discussion of the influence of viscosity on this variable are included in Section III and tentative conclusions are drawn in Section VI.

This paper investigates the ambient pressure on the spray characteristics like spray cone angle in a specially designed and fabricated constant volume spray chamber by employing shadow technique The constant volume chamber has been designed to be able to withstand an ambient pressure up to 10 bars. The image analyzed was chosen of spray visualization instruments consisting of an oil sheet, white light source.

Bio-diesel, which can be used as an alternative diesel fuel, is made from renewable biological sources such as vegetable oil and animal fats. It is biodegradable, non-toxic and possesses low emission profiles. Also, the uses of bio-fuels are environmentally beneficial. Chemically, bio-diesel is referred to as the mono-alkyl-esters of long-chain-fatty acids derived from renewable lipid sources. Bio-diesel is the name for a variety of ester based oxygenated fuel from renewable biological sources [3, 4].

This paper summarizes the result of an experimental investigation carried out to examine the spray characteristics of a fuel injector from a biodiesel, kerosene and water. This paper is organized as follows. First of all, experiment facilities and setup are briefly described. Secondly, spray cone angle obtained from a variety of fluids are illustrated and discussed. Finally, conclusive remarks are provided.

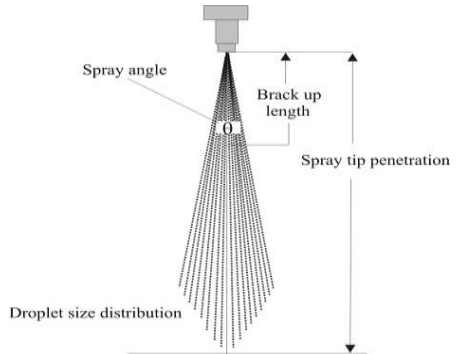

Fig. 1. Physical parameters of a fuel spray ${ }^{[1]}$ 


\section{INJECTOR}

Chamber

The injector design has always been recognized as a key component that often controls the success or failure of the combustion device.

\section{A. Concept of injector}

The conversion of potential energy of the liquid in the form of pressure drop across the injector into kinetic energy of a liquid jet, which subsequently produces a spray of droplets. This atomization principle is used for jet, film, and swirl injectors.

\section{B. Injector Assembly}

The general criteria for injector design are to atomization and dispersion of fuel flow. The degree of atomization required depends primarily upon the time available for vaporization mixing process. The simplex type injector is used for the experiment for finding spray cone angle. In this injector, the fluid is caused to swirl

K.Vinukumar; Lecturer; Department of Mechanical Engineering; Holycross Engineering College; Thoothukudi district; Tamil Nadu; India (Corresponding author to provide phone: +91 7598407598; Email: er.vinukumar@gmail.com )

by tangential slots. The high velocity causes an air core vortex so that the fluid forms a hollow cone as it comes out of the injector. Inside the injector the injector cone material made with brass and it has four holes and below one tangential hole is provided. The spray cone angle is as large as up to $90^{\circ}$. The material of construction for the injector is SS316. The injector assembly has filter, injector cone, bottom screw, injector housing, are shown in Fig.2.

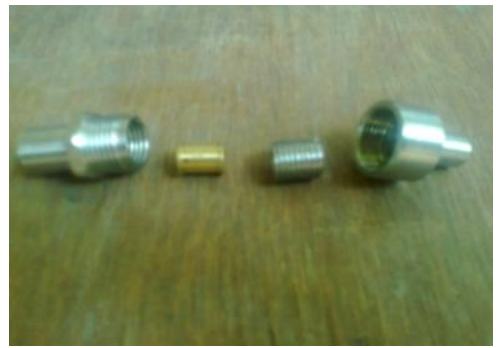

Fig.2.Injector assembly

\section{DESIGN CONSIDERATIONS AND SPRAY PREDICTIONS}

The following data are required for an injector design. The flow number, $F N=6.2263 \times 10^{-6} \mathrm{~m}^{2}$, is calculated using Equation (1)

$$
\text { Where } m_{\mathbb{L}} \text { the liquid mass } F N=\frac{m_{L}^{n}}{\sqrt{P_{L} \times \Delta P_{L}}}-(1)
$$

flow rate is taken as $0.10089 \mathrm{~kg} / \mathrm{s}, \rho_{\mathrm{L}}$ is the liquid density as $875.2 \mathrm{~kg} / \mathrm{m}^{3}$, and $\Delta P_{L}$ is the injector pressure differential as $3 \times 10^{5} \mathrm{~N} / \mathrm{m}^{2}$, velocity of fluid as $D_{L}=39.8076 \mathrm{~m} / \mathrm{s}$, for finding $C d$ and $\Delta P_{L}$ is the injector pressure differential as $8 \times 10^{5} \mathrm{~N} / \mathrm{m}^{2}$.

Design discharge coefficient for one phase liquid flow as $C d=0.93$ is calculated using equation (2)

$$
C d=\frac{D_{L} \times \rho_{L}}{\left(2 \times \rho_{L} \times \Delta P_{L}\right)^{0.5}}-(2)
$$

The dimensionless group discharge coefficient, $C d$, which can be calculated by the Equation (2).Empirical relations for $C d$ developed by Carlisle [10]. The discharge coefficient was calculated using the expression

Discharge coefficient $(C d)$ for

$$
C d=\frac{m_{L}}{A_{0} \times \sqrt{2 \times p_{L} \times \Delta P_{L}}}-(3)
$$

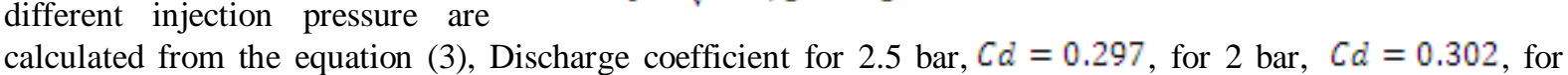
1.5 bar, $C d=0.314$, for 1 bar, $C d=0.320$, for 0.5 bar, $C d=0.362$

Several formulae have been derived to express the spray angle in terms of nozzle dimensions and the relevant air and liquid properties. The simplest expression for the spray angle is given by the jet mixing theory of Abramovich [9] as

$$
\tan \theta=0.13\left(1+\frac{\rho_{A}}{\rho_{L}}\right)-(4)
$$

According to Reitz and Bracco[18], the spray angle can be determined by combining the radial velocity of the fastest growing of the unstable surface waves with the axial injection velocity. This hypothesis results in the following expression (5) for the spray angle:

$$
\text { www.iosrjournals.org }
$$




$$
\tan \theta=\frac{2 \pi}{\sqrt{3 A}}\left(\frac{\rho_{A}}{\rho_{L}}\right)^{0.55}-(5)
$$

Property value of gases at one atmospheric pressure for $30^{\circ} \mathrm{C}$ (From heat and mass transfer data book page no: 24), Density of air, $\rho_{A}=1.165 \mathrm{~kg} / \mathrm{m}^{3}$, Density of biodiesel, $\rho_{\mathrm{L}}=875.2 \mathrm{~kg} / \mathrm{m}^{3}$, Spray cone angle, $\theta=89.48^{\circ}$

\section{EXPERIMENTAL SETUP}

The experimental setup for the measurement of spray cone angle is shown in Fig.3. The Shadow graphic Technique is used to find the spray cone angle. The simplex injector was removed from the combustor assembly and mounted into a cylindrical fuel tank. The fuel tank was fitted with a pressure gauge to monitor the pressure across the nozzle.

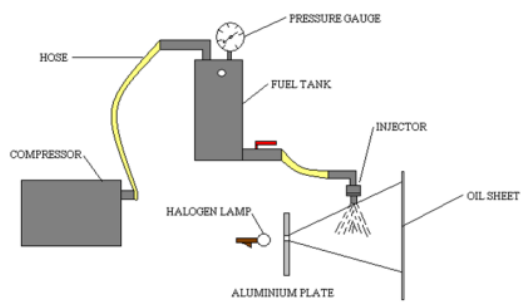

Fig. 3 Experimental Setup for spray analysis

A fuel surrogate, biodiesel and kerosene (injector calibrating fluid) was supplied to the injector. The compressor and fuel tank are connected with hose. The air inlet was fed to fuel tank with the help of compressor. The fuel tank (FT) contains the fuel. Its volume is 3 liters. The injector is vertically oriented, injecting the liquid downward. The spray is discharged into an open quiescent environment. The cloud of droplets is collected by an extraction system placed under the injector.

. The Shadow graphic technique based on a back-light Halogen lamp is used. And aluminum plate with $2 \mathrm{~mm}$ diameter hole is provided. Oil sheet was used to determine the spray cone angle and visually inspect the spray at various operating conditions.

\section{RESULTS AND DISCUSSION}

It is well understood that the combination of liquid inertia, surface tension and aerodynamic forces affects the liquid breakup. Liquid breakup characteristics such as the spray drop size, the breakup length, and the spray cone angle are related to the unstable wave growing process.

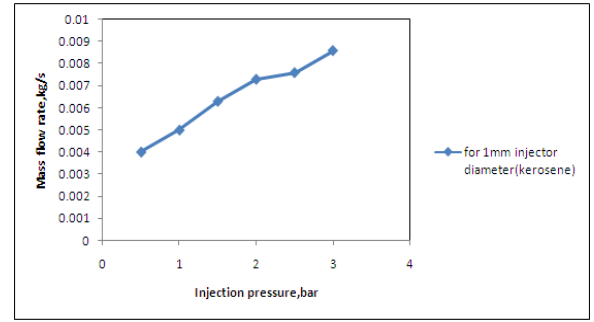

Fig. 4. Mass flow rate (Kerosene) as a function of the injection pressure.

Kerosene is sprayed in the test chamber from injector having spray cone angle of $51^{\circ}, 49^{\circ}, 45^{\circ}, 43^{\circ}, 40^{\circ}$ and $35^{\circ}$ at injection pressure of 3 bar, 2.5 bar, 2 bar, 1.5 bar, 1 bar and 0.5 bar, with constant $1 \mathrm{~mm}$ injector diameter. And constant $1 \mathrm{~mm}$ injector diameter at injection pressure of $3 \mathrm{bar}, 2.5 \mathrm{bar}, 2 \mathrm{bar}, 1.5 \mathrm{bar}, 1 \mathrm{bar}$ and 0.5 bar the mass flow rate of injector are $0.0086 \mathrm{~kg} / \mathrm{s}, 0.0076 \mathrm{~kg} / \mathrm{s}, 0.0073 \mathrm{~kg} / \mathrm{s}, 0.0063 \mathrm{~kg} / \mathrm{s}, 0.005 \mathrm{~kg} / \mathrm{s}, 0.004 \mathrm{~kg} / \mathrm{s}$.

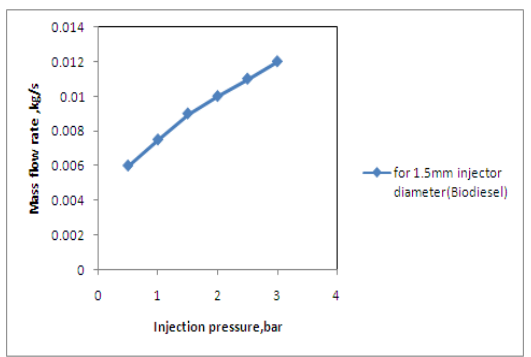

Fig. 5. Mass flow rate (Biodiesel) as a function of the injection pressure.

WWW.iosrjournals.org 
From the experimental results, it is seen that the fluid viscosity plays a very important role in controlling the liquid sheet breakup and atomization. The spray cone angle degrees were also calculated for the experimental fluids. For fluids with different viscosities, it is found that more viscous biodiesel have smaller average spray cone angles. The spray cone developed very fast during the early stage for less viscous fluids, while for very viscous liquid, a very small cone angle with little breakup and atomization was observed.

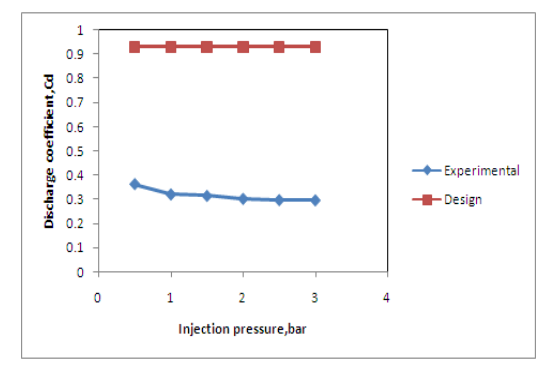

Fig. 6. Discharge coefficient as a function of the injection pressure.

As observed in Figure 8 the spray cone angle decrease as the liquid viscosity increases. Spray Cone angle about $4^{\circ}$ difference comparing kerosene and biodiesel for 3 bar injection pressure.

Figure 6 shows the discharge coefficient as functions of injector pressure. Figure 6 also shows the $C_{d}$ used in the injector design and calculated with Carlisle equations (Equations 2). The experimental results are quite close to the design values. For instance, at the design pressure differential of 3 bar the discharge coefficient were 0.296, quite close to the design values of 0.93. From experimental results Figure 6 shows that injector pressure increases as the discharge coefficient decreases.

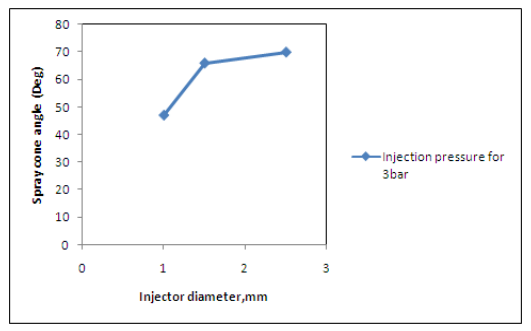

Fig. 7. Spray cone angle as a function of injector diameter.

The pressure differential applied through the injector ranged from 0.5 bar to 3 bar. Under 0.5 bar, the liquid discharge did not generate a typical spray, but only a smooth film was formed around a hollow bubble resembling an onion; i.e., of no practical interest. On the other side, 10 bar was the limiting pressure for the reservoir.

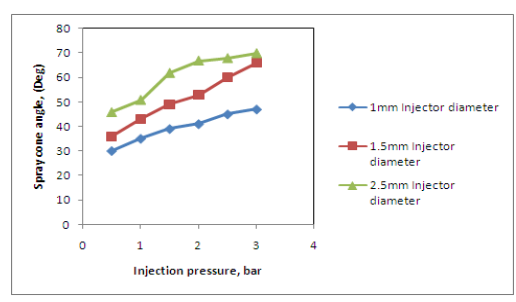

Fig. 8. Spray cone angle as a function of the injection pressure.

Figure 4 and 5 shows the liquid mass flow rate and Figure 8 the spray cone angle, both as functions of injector pressure. It is also possible to notice that the spray angle increases when the pressure differential increases, and the liquid film length is reduced. The injection pressure at 3 bar the mass flow rate is $0.0086 \mathrm{Kg} / \mathrm{s}$ for $1 \mathrm{~mm}$ injector diameter. Different fuels such as water, kerosene and biodiesel injection pressure at 3 bar the spray cone angle for water $52 \mathrm{deg}$, for kerosene $51 \mathrm{deg}$ and for biodiesel $47 \mathrm{deg}$ for same injection pressure and same $1 \mathrm{~mm}$ injector diameter. For fluids with different viscosities, it is found that more viscous biodiesel have smaller average spray cone angles.

Figure 7 shows the spray cone angle increasing as the injector diameter increases, which is expected for the injector was not changed, i.e., it was kept with the different injector dimensions, and the mass flow rate also increases with the injector pressure as it was shown in Figure 4 and 5.

$$
\text { www.iosrjournals.org }
$$


Based on the theoretical and experimental investigations the spray angle is an inverse function of the injection pressure. However, this was so because in those investigations the injection pressure was analyzed in an isolated manner, the injector dimensions were adjusted to fit the desired condition.

\section{CONCLUSIONS}

Experimental measurements were carried out to estimate the spray cone angle of water, kerosene, and bio diesel fuel jets are injected in an inert environment. The effects of the characteristic parameters, i.e. the injector diameter, discharge coefficient, injection pressure, and working fluid density were analyzed. The different fuel spray cone angle was recorded using the shadow graphic technique.

From experimental results shows that injector pressure increases as the discharge coefficient decreases. An increase in the injection pressure causes an increase in the cone angle up to a maximum value, above decrease gradually. The spray cone angle increases as the injector diameter increasing. And the mass flow rate also increases with the injector pressure and injector diameter.

In this work different injector dimensions was investigated and this was done in a limited range of injector pressure, for the intent was the comparison of parameters at the design point $(\Delta \mathrm{P}=3$ bar $)$. Hence, for more conclusive results it would be interesting to compare different design conditions.

\section{ACKNOWLEDGMENT}

This experimental work has been done under the support of Er.Manoher, VAIGUNTH ENER TEK (P) LTD. Chennai- 600 100, Tamil Nadu, India.

\section{REFERENCES}

[1] Xu M. y Hiroyasu H. (1990) "Development of a New Optical Technique for Measuring Diesel Spray Penetration". SAE Technical Paper 902077.

[2] Pedro Teixeira Lacava*, Demétrio Bastos-Netto**, Amílcar Porto Pimenta*Design Procedure And Experimental Evaluation Of Pressure-Swirl Atomizers, Icas2004 $24^{\text {th }}$ International Congress Of The Aeronautical Sciences.

[3] FangruiMaa, Milford A. Hannab, Bioresource. Biodiesel production: a review, Technology 70 (1999).

[4] AS Ramadhas, S Jayaraj, C Muraleedharan. Use of vegetable oils as I.C. engine fuels-a review. Renewable Energy $2004 ; 29$.

[5] Digvijay B. Kulshreshtha, Saurabh Dikshit and S. A. Channiwala Experimental investigations of air assisted pressure swirl atomizer, Indian Journal of Science and Technology, Vol. 4 No. 2 (Feb 2011) ISSN: 0974- 6846.

[6] Arthur H.Lefebvre and Dilip R.Ballal, Gas turbine combustion alternative fuels and emissions.

[7] Javier Ballester, Cesar Dopazo, Discharge coefficient and spray angle measurements for small pressure-swirl nozzles, Atomization and Sprays, vol. 4, pp. 351-367, 1994

[8] Digvijay B. Kulshreshtha, Saurabh Dikshit and S. A. Channiwala Experimental investigations of air assisted pressure swirl atomizer, Indian Journal of Science and Technology, Vol. 4 No. 2 (Feb 2011) ISSN: 0974- 6846.

[9] Abramovich, G.N., Theory of Turbulent Jets, MIT press, Cambridge, MA,1963.

[10] Carlisle D R. Communication on the Performance of a Type of Swirl Atomizer, by A. Radcliffe. Proc. Inst. Mech. Eng., Vol. 169, p.101, 1955 .

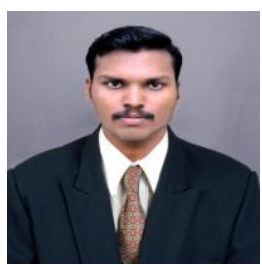

K.Vinukumar was born in the year $07^{\text {th }}$ November 1986. He has completed his post graduate in Thermal Engineering in the year 2011 from Anna University of Technology Tirunelveli. Presently he is working as Lecturer in Mechanical Engineering at Holy cross Engineering College, Thoothukudi District; Tamil Nadu; India. He has a year of experience in teaching. His field of interest is Alternative fuels. He has presented papers on alternative fuels in many International and National conferences. 